\title{
Kajian Keruangan Pola Sebaran Strategi Pembelajaran Dalam Kegiatan PPL II (Studi Kasus: Mahasiswa S1 Pendidikan Geografi Universitas Nusa Cendana di Kota Kupang)
}

\author{
Space Study on the Distribution Pattern of Learning Strategies in PPL II Activity \\ (Case Study: Undergraduate Students of Geography Education on Nusa Cendana University \\ in Kupang)
}

Arfita Rahmawati ${ }^{1}$, Radhi Ariawan ${ }^{2}$

${ }^{1}$ Program Studi Pendidikan Geografi, FKIP, Universitas Nusa Cendana

${ }^{2}$ Teknik Mesin, Politeknik Negeri Cilacap

\begin{abstract}
ARTICLE INFO
Article history:

DOI:

10.30595/pssh.v1i.75

Submitted:

April 12, 2021

Accepted:

June 10, 2021

Published:

June 14, 2021

Keywords:

PPL II, spatial pattern, learning strategy, NNA

ABSTRACT

Practical Field Experience (PPL) II is a compulsory subject, especially for prospective teachers. Practical Field Experience (PPL) II is a time for teaching students to practice learning knowledge in school partners. The Covid-19 pandemic occurred changed the PPL II system from offline to online. The online PPL system provides new experiences for students, including in determining the learning strategies to use. The purpose of this study to determine the distribution patterns of learning strategies in PPL II so can saw the learning strategies that are most popular among students and their spatial patterns. This study used questionnaire data that was distributed to 88 students then carried out NNA analysis to determine the spatial pattern and linear regression analysis. Based on the research results, it is known that the popular learning strategy used by students when PPL II is a cooperative learning strategy with a value of $44.318 \%$. The spatial pattern based on the distribution of learning strategies used for cooperative learning, contextual and Problem Based Learning is clustered or clustered. As for the random patterned inquiry learning strategy. There is an influence from the learning strategies used by students on the level of satisfaction of school partners.

This work is licensed under a Creative Commons Attribution 4.0 International License.

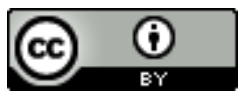

Corresponding Author:

Arfita Rahmawati

Program Studi Pendidikan Geografi,

Fakultas Keguruan dan Ilmu Pendidikan, Universitas Nusa Cendana

Jalan Laksda. Adi Sucipto, Penfui, Kota Kupang, Nusa Tenggara Timur, Indonesia

Email: arfitarahmawati@staf.undana.ac.id

1. PENDAHULUAN

Di tahun 2019 kasus pneumonia misterius pertama kali dilaporkan di Wuhan, Provinsi Hubei, sumber penularan kasus ini masih belum diketahui pasti, tetapi kasus pertama dikaitkan dengan pasar ikan di Wuhan [1]. Manifestasi klinis pasien COVID-19 memiliki spektrum yang luas, mulai dari tanpa gejala (asimtomatik), gejala ringan, pneumonia, pneumonia berat, ARDS, sepsis, hingga syok sepsis. Sekitar $80 \%$ kasus tergolong ringan atau sedang, 13,8\% mengalami sakit berat, dan sebanyak 6,1\% pasien jatuh ke dalam keadaan kritis [2]. Case fatality rate (CFR) negara Indonesia juga jauh lebih tinggi daripada di Republik Rakyat Cina (8,9\% vs 4\%), sehingga WHO mengumumkan COVID-19 pada 12 Maret 2020 sebagai pandemi [3].
\end{abstract}


Pandemi Covid-19 yang terjadi di Indonesia memberikan dampak dalam berbagai bidang, salah satunya adalah kebijakan di bidang pendidikan. Selama pandemi, sekolah ditutup tetapi proses pembelajaran harus dilanjutkan [4]. Salah satunya adalah bidang pendidikan, Kementerian Pendidikan dan Kebudayaan sampai mengeluarkan Surat Edaran Mendikbud Nomor 4 Tahun 2020 tentang Pelaksanaan Pendidikan Dalam Masa Darurat Coronavirus Disease (Covid-19) dan Surat Edaran Nomor 15 Tahun 2020 tentang Pedoman Penyelenggaraan Belajar Dari Rumah Dalam Masa Darurat Penyebaran Covid-19. Penerapan pembelajaran online adalah bukti dari revolusi industri 4.0, di mana akses ke teknologi berada tidak terbatas, sehingga memungkinkan implementasi online atau pembelajaran jarak jauh $[5]$.

Guru sebagai unsur utama dalam pendidikan formal didorong untuk beradaptasi dengan pelaksanaan pembelajaran yang semula menggunakan metode tatap muka konvensional dan beralih ke pembelajaran online [6]Perguruan tinggi wajib mengatasi masalah rendahnya kulitas guru. dengan mempersiapkan calon-calon guru harus benar-benar secara matang [7]. Salah satunya dengan adanya mata kuliah Praktik Pembelajaran Lapangan (PPL). Mata kuliah PPL yang diselenggarakan di Fakultas Keguruan dan Ilmu Pendidikan, Universitas Nusa Cendana terdiri dalam dua tahap, yaitu PPL 1 dan PPL II. Praktik Pembelajaran Lapangan I (PPL I) merupakan mata kuliah untuk mempersiapkan mahasiswa tentang dasar-dasar mengajar seperti strategi pembelajaran, model pembelajaran, teknik pembelajaran, hingga pembuatan media pembelajaran. Sedangkan untuk Praktik Pembelajaran Lapangan II (PPL II) merupakan mata kuliah yang menekankan penerapan dan pengaplikasian pengetahuan mengajar yang didapatkan mahasiswa terhadap sekolah mitra.

Berpedoman pada urat Edaran Mendikbud Nomor 4 Tahun 2020 tentang Pelaksanaan Pendidikan Dalam Masa Darurat Coronavirus Disease (Covid-19) dan Surat Edaran Nomor 15 Tahun 2020 tentang Pedoman Penyelenggaraan Belajar Dari Rumah Dalam Masa Darurat Penyebaran Covid-19 menyebabkan perubahan sistem terhadap pelaksanaan PPL II. Mata kuliah Praktik Pembelajaran Lapangan yang berciri khas datang ke sekolah mitra dan masiswa melakukan praktik pembelajaran dengan tatap muka berubah menjadi daring.

Strategi erat kaitannya dengan teknis dalam melaksanakan pembelajaran [8]. Strategi pembelajaran bermanfaat untuk menanamkan pengetahuan serta untuk mengembangkan keterampilan belajar secara efektif [9]. Penentuan strategi pembelajaran dapat memberikan gambaran mengenai prosedur yang digunakan guru dalam mencapai tujuan pembelajaran.

Penelitian ini bertujuan untuk mengetahui pola keruangan berdasarkan strategi pembelajaran yang digunakan oleh mahasiswa dalam kegiatan PPL II selama masa pandemic Covid-19. Sehingga dapat diketahui karakteristik strategi pembelajaran yang mudah diaplikasikan oleh mahasiswa dalam masa pandemi Covid-19 dan tanggapan dari sekolah mitra yang menjadi fasilitator penerapan strategi pembelajaran tersebut

\section{METODE PENELITIAN}

Penelitian yang digunakan dalam penelitian ini adalah penelitian deskriptif dengan pendekatan kuantitatif. Penelitian deskriptif yaitu, penelitian yang dilaksanakan dengan tujuan untuk mengetahui nilai dari variabel mandiri yang berjumlah minimal satu variabel tanpa membuat komparasi, atau mengkorelasikan dengan variabel yang lain [10]. Jumlah populasi yang digunakan adalah mahasiswa Pendidikan geografi Universitas Nusa Cendana yang memprogram mata kuliah PPL II sebanyak 114 mahasiswa. Untuk sampel menggunakan rumus Slovin sehingga jumlah sample representative.

$$
n=\frac{n}{1+\left(n x e^{2}\right)}
$$

Berdasarkan hasil perhitungan didapatkan jumlah sampel yang digunakan ada 88 mahasiswa. Pengumpulan data dilakukan dengan pemberian angket kepada mahasiswa melalui aplikasi kobotoolbox sehingga lokasi mahasiswa dapat terekam. Dari data yang didapatkan selanjutkan dilakukan input data ke dalam peta administrasi Kota Kupang. Untuk mengetahui pola keruangan digunakan analisis tetangga terdekat (Near Neighbour Analysis atau NNA). Pola penggunaan strategi pembelajaran yang digunakan saat PPL II terjadi jika terdapat persebaran mahasiswa yang memprogram mata kuliah PPL II. Analisis regresi linier digunakan untuk mengetahui pengaruh strategi pembelajaran yang digunakan terhadap tingkat kepuasan sekolah mitra.

\section{HASIL DAN PEMBAHASAN}

Berdasarkan dari hasil penelitian didapatkan hasil sebagai berikut:

a. Sebaran Lokasi Mahasiswa

Sebaran lokasi mahasiswa yang melaksanakan kegiatan PPL II tersebar di Kota Kupang disajikan dalam tabel berikut:

Tabel 1. Sebaran Mahasiswa Per-Kecamatan di Kota Kupang

\begin{tabular}{lcc}
\hline Kecamatan & Jumlah & Persentase $(\%)$ \\
\hline
\end{tabular}




\begin{tabular}{lll}
\hline Alak & 5 & 5,68 \\
Kota Raja & 3 & 3,41 \\
Kota Lama & 2 & 2,27 \\
Maulafa & 18 & 20,45 \\
Oebobo & 12 & 13,64 \\
Kelapa Lima & 48 & 54,55 \\
\hline
\end{tabular}

Sumber: Hasil Penelitian, 2021

Berdasarkan tabel 1 diketahui paling banyak mahasiswa berada di kecamatan Kelapa lima dengan jumlah 48 mahasiswa atau sebanyak 54,55\%. Sedangkan paling sedikit berada di Kecamatan Kota Lama dengan jumlah 2 mahasiswa atau $2,27 \%$. Hasil petanya sebagai berikut:

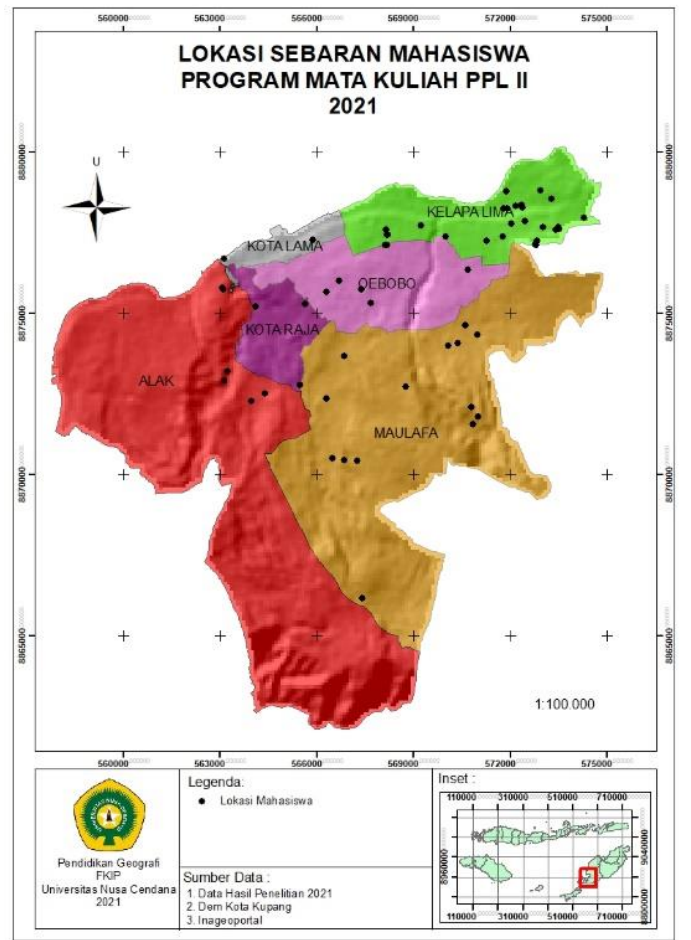

Gambar 1. Lokasi Sebaran Mahasiswa Program Mata Kuliah PPL II

b. Strategi Pembelajaran yang digunakan

Strategi pembelajaran yang digunakan oleh mahasiswa dalam kegiatan PPL II sebagai berikut:

Tabel 2. Strategi Pembelajaran yang Digunakan Mahasiswa dalam Kegiatan PPL II

\begin{tabular}{lcc}
\hline \multicolumn{1}{c}{ Strategi Pembelajaran } & Jumlah & $\%$ \\
\hline Inkuiri & 14 & 15,90909091 \\
Kooperatif & 39 & 44,31818182 \\
Kontekstual & 14 & 15,90909091 \\
Problem Based Learning & 21 & 23,86363636 \\
\hline
\end{tabular}

Sumber: Hasil Penelitian, 2021

Berdasarkan tabel 2 diketahui strategi pembelajaran yang paling banyak digunakan oleh mahasiswa saat kegiatan PPL II adalah kooperatif dengan jumlah mahasiswa yang menggunakan ada 39 orang atau sebesar 44,318\%. Berikut disajikan peta sebaran strategi pembelajaran yang digunakan oleh mahasiswa: 


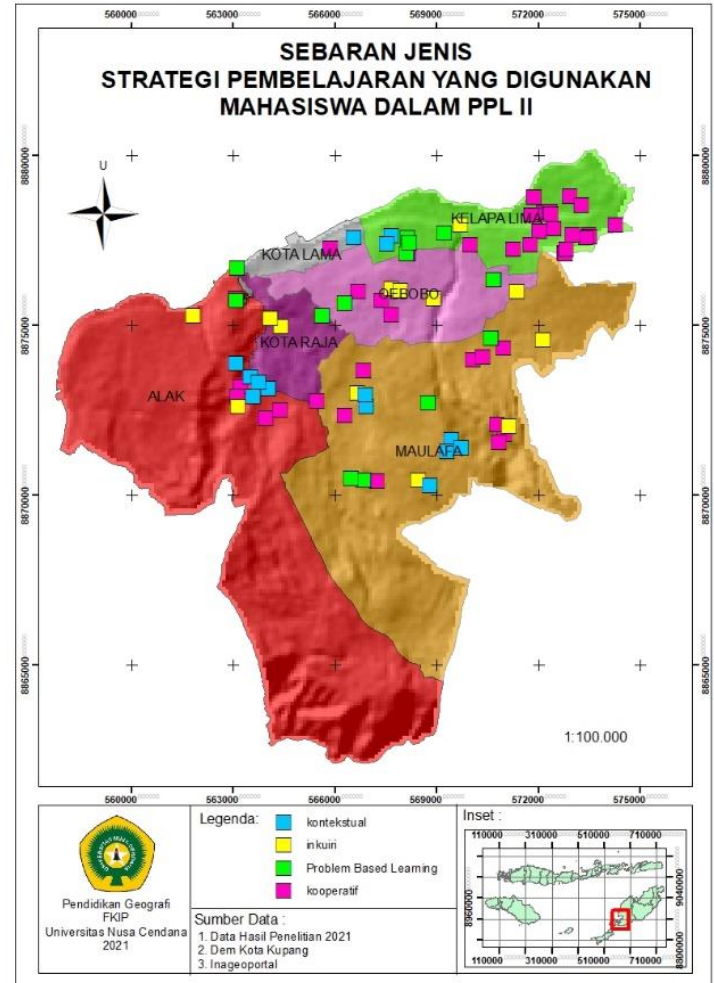

Gambar 2. Sebaran Pembelajaran yang Digunakan Mahasiswa dalam PPL II

c. Pola Keruangan Strategi Pembelajaran

Pola keruangan didapatkan dari hasil analisis tetangga terdekat (NNA). Dengan menggunakan perhitungan analisa tetangga terdekat, dapat ditentukan pola keruangannya dengan menghitung parameter jarak rata-rata satu titik dibagi dengan jarak rata-rata semua titik. Selanjutnya diinterpretasikan polanya mengelompok, acak, atau seragam. Hasilnya sebagai berikut:

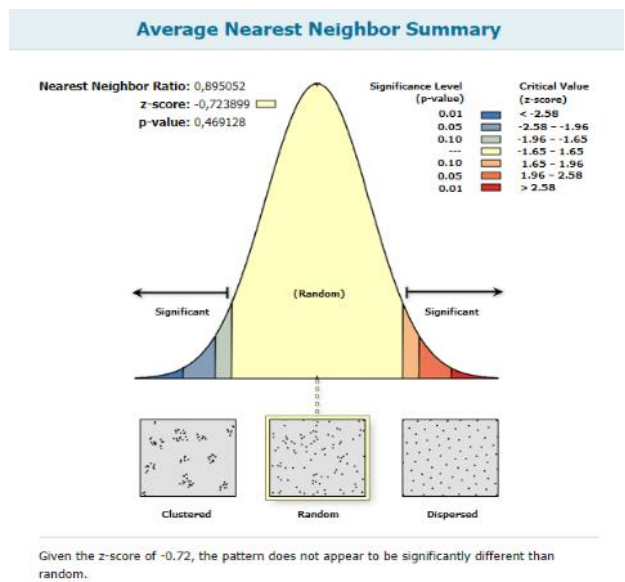

Gambar 3. Pola Keruangan Strategi Pembelajaran Inkuiri 


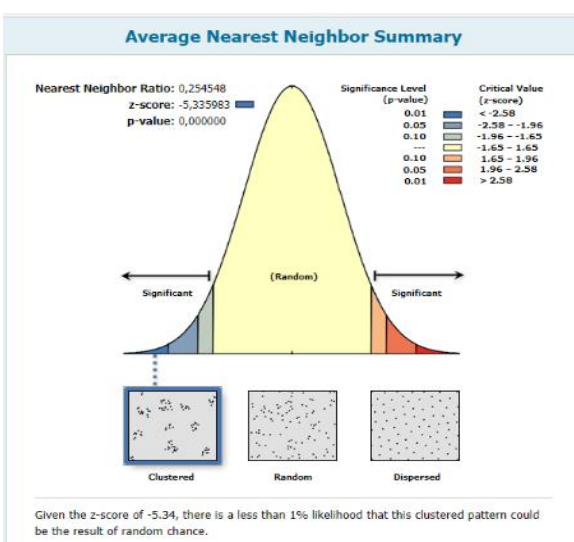

Gambar 4. Pola Keruangan Strategi Pembelajaran Kontekstual

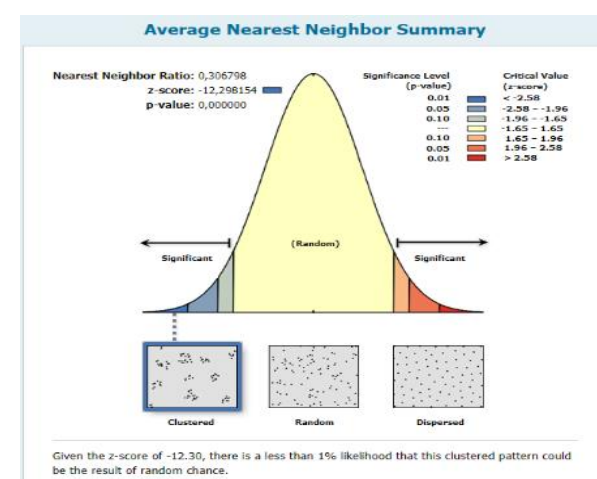

Gambar 5. Pola Keruangan Strategi Pembelajaran Kooperatif

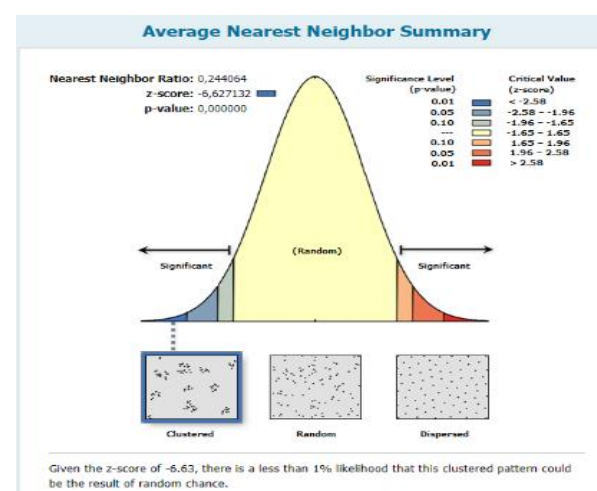

Gambar 6. Pola Keruangan Strategi Pembelajaran Problem Based Learning

Diketahui dari gambar 3, pola keruangan strategi pembelajaran inkuiri berpola random atau acak, hal ini menunjukan Jarak mahasiswa yang menggunakan strategi pembelajaran inkuiri lokasi satu dengan lokasi lainnya tidak teratur. Sedangkan pada gambar 4, 5, dan 6 pola keruangan strategi pembelajaran kontekstual, kooperatif, dan problem based learning berpola mengelompok. Hal ini menunjukan jarak mahasiswa yang menggunakan strategi pembelajaran satu dengan lainnya lokasinya berdekatan dan cenderung mengelompok di lokasi-lokasi tertentu

d. Tingkat Kepuasan Sekolah Mitra terhadap Strategi Pembelajaran yang Digunakan Jumlah sekolah mitra dalam pelaksanaan kegiatan PPL II periode semester ganjil tahun pelajaran 2020-2021 sejumlah 36 sekolah mitra baik negeri maupun swasta. Berikut hasil tingkat kepuasan sekolah mitra terhadap strategi pembelajaran yang digunakan oleh mahasiswa yang melaksanakan kegiatan PPL II. 
Tabel 3. Tingkat Kepuasan Sekolah Mitra

\begin{tabular}{lcc}
\hline \multicolumn{1}{c}{ Tingkat Kepuasan } & Jumlah & Persentase $(\%)$ \\
\hline Sangat puas & 23 & 63,889 \\
Puas & 7 & 19,444 \\
Tidak puas & 6 & 16,667 \\
\hline
\end{tabular}

Sumber: Hasil Penelitian, 2021

Dari tabel 3 dapat diketahui sejumlah 23 sekolah mitra atau 63,889\% merasa sangat puas dengan strategi pembelajaran yang digunakan oleh mahasiswa yang mengikuti kegiatan PPL II. Sedangkan 6 sekolah mitra atau sebesar $16,667 \%$ merasa tidak puas.

e. Pengaruh Strategi Pembelajaran yang digunakan Terhadap Tingkat Kepuasan Sekolah Mitra

Dasar pegambilan keputusan dalam uji regresi linear untuk mengetahui pengaruh strategi pembelajaran yang digunakan terhadap tingkat kepuasan sekolah mitra dapat mengacu pada dua hal yakni membandingkan nilai signifikansi dengan nilai probabilitas dan membandingkan $t_{\text {hitung }}$ dengan $t_{\text {tabel. }}$.

1) Uji Determinasi (R Square )

Koefisien determinasi (R Square) bertujuan untuk mengetahui seberapa besar kemampuan variabel independen yang digunakan mampu menjelaskan variabel depende. Berikut ini hasil uji determinasi (R Square):

Tabel 4. Hasil Uji Determinasi

Model Summary

\begin{tabular}{|l|l|r|r|r|}
\hline $\begin{array}{l}\text { Mode } \\
1\end{array}$ & R & R Square & $\begin{array}{c}\text { Adjusted R } \\
\text { Square }\end{array}$ & $\begin{array}{c}\text { Std. Error of } \\
\text { the Estimate }\end{array}$ \\
\hline 1 & $.864^{2}$ & .747 & .743 & .315 \\
\hline
\end{tabular}

a. Predictors: (Constant), Strategi Pembelajaran

Berdasarkan tabel hasil uji determinasi (R Square) di atas menjelaskan besarnya nilai korelasi atau hubungan (R) yaitu sebesar 0,864. Dari output tersebut diperoleh koefisien determinasi (R Square) sebesar 0,747 , yang mengandung pengertian bahwa pengaruh variabel bebas (strategi pembelajaran) terhadap variabel terikat (tingkat kepuasan) adalah sebesar 7,47\%.

2) Uji Anova

Tabel 4. Hasil Uji Determinasi

\begin{tabular}{|c|c|c|c|c|c|c|}
\hline \multicolumn{7}{|c|}{ ANOVA } \\
\hline Madel & & $\begin{array}{l}\text { Sum of } \\
\text { Squares }\end{array}$ & df & Mean Square & $\mathrm{F}$ & Sig. \\
\hline 1 & Regression & 19.842 & 1 & 19.842 & 200.484 & $000^{2}$ \\
\hline & Residual & 6.730 & 68 & .099 & & \\
\hline & Total & 26.571 & 69 & & & \\
\hline
\end{tabular}

Pada tabel ANOVA dapat diketahui bahwa nilai $\mathrm{F}$ hitung $=200,484$, dengan tingkat signifikansi sebesar $0,000<0,05$, maka model regresi dapat dipakai untuk memprediksi variabel tingkat kepuasan atau dengan kata lain ada pengaruh variabel strategi pembelajaran $(\mathrm{x})$ terhadap variabel tingkat kepuasan (y). 
3) Uji T

Tabel 5. Hasil Persamaan Regresi Linear Sederhana

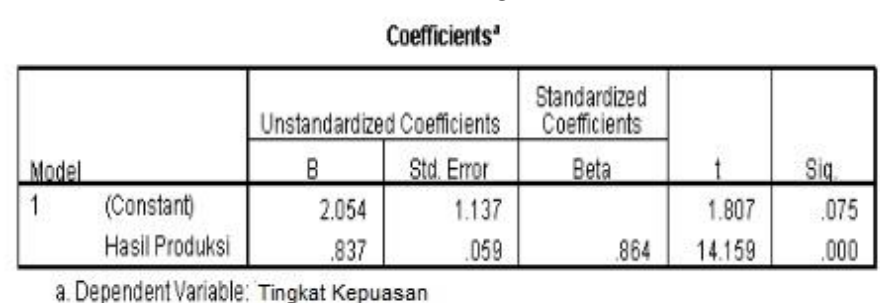

Dari tabel output hasil persamaan regresi linear sederhana diketahu nilai constant (a) sebesar 2,054, sedangkan nilai hasil produksi (b/koefisien regresi) sebesar 0,837 , sehingga persamaan regresinya dapat ditulis :

$$
\begin{gathered}
\mathrm{Y}=\mathrm{a}+\mathrm{bX} \\
\mathrm{Y}=2,054+0,837
\end{gathered}
$$

Berdasarkan nilai signifikansi: dari tabel coefficients diperoleh nilai signifikan sebesar $0,000<0,05$, sehingga dapat disimpulkan bahwa variabel strategi pembelajaran $(\mathrm{X})$ berpengaruh terhadap variabel tingkat kepuasan (Y). Berdasrkan nilai t: diketahui nilai t hitung sebesar 14,159 > t tabel 0,1982, sehingga dapat disimpulkan bahwa variabel strategi pembelajaran $(\mathrm{X})$ berpengaruh terhadap variabel tingkat kepuasan $(\mathrm{Y})$

\section{KESIMPULAN}

Berdasarkan pada hasil analisis data dan pembahasan, maka dapat ditarik kesimpulan sebagai berikut :

a. Strategi pembelajaran yang populer digunakan oleh mahasiswa saat PPL II adalah strategi pembelajaran kooperatif dengan nilai 44,318\%. Sedangkan strategi pembelajaran yang jarang digunakan adalah strategi pembelajaran inkuiri dan kontekstual dengan nilai $15,90 \%$.

b. Pola keruangan strategi pembelajaran inkuiri berpola random atau acak, hal ini menunjukan jarak mahasiswa yang menggunakan strategi pembelajaran inkuiri lokasi satu dengan lokasi lainnya berpola tidak teratur

c. Pola keruangan strategi pembelajaran kontekstual, kooperatif, dan problem based learning berpola mengelompok. Hal ini menunjukan jarak mahasiswa yang menggunakan strategi pembelajaran satu dengan lainnya lokasinya berdekatan dan cenderung mengelompok di lokasi-lokasi tertentu.

d. Sejumlah 23 sekolah mitra atau $63,889 \%$ merasa sangat puas dengan strategi pembelajaran yang digunakan oleh mahasiswa yang mengikuti kegiatan PPL II

e. Nilai t hitung sebesar 14,159>t tabel 0,1982, sehingga dapat disimpulkan bahwa strategi pembelajaran berpengaruh terhadap tingkat kepuasan sekolah mitra

\section{DAFTAR PUSTAKA}

[1] H. A. Rothan and S. N. Byrareddy, "The epidemiology and pathogenesis of coronavirus disease (COVID-19) outbreak," Journal of Autoimmunity, vol. 109. Academic Press, p. 102433, May 01, 2020, doi: 10.1016/j.jaut.2020.102433.

[2] C. A. Glass, J. C. Cash, and J. Mullen, “Coronavirus Disease (COVID-19)," Fam. Pract. Guidel., no. October, 2020, doi: 10.1891/9780826153425.0016b.

[3] R. N. Putri, “Indonesia dalam Menghadapi Pandemi Covid-19,” J. Ilm. Univ. Batanghari Jambi, vol. 20, no. 2, p. 705, 2020, doi: 10.33087/jiubj.v20i2.1010.

[4] L. Sun, Y. Tang, and W. Zuo, “Coronavirus pushes education online,” Nat. Mater, vol. Jun;19(6), no. 687, 2020, doi: 10.1038/s41563-020-0678-8.

[5] A. Medical Association, "Letters Presumed Asymptomatic Carrier Transmission of COVID-19," 2020, doi: 10.1001/jama.2020.2565.

[6] M. Suryaman et al., "COVID-19 pandemic and home online learning system: Does it affect the quality of pharmacy school learning?,” Syst. Rev. Pharm., vol. 11, no. 8, pp. 524-530, 2020, doi: 10.31838/srp.2020.8.74.

[7] A. Yulianto and M. Khafid, "Pengaruh Praktik Pengalaman Lapangan (Ppl), Minat Menjadi Guru, Dan Prestasi Belajar Terhadap Kesiapan Mahasiswa Menjadi Guru Yang Profesional,” Econ. Educ. Anal. J., vol. 5, no. 1, pp. 100-114, 2016.

[8] F. Fatimah and R. D. Kartikasari, "Strategi Belajar Dan Pembelajaran Dalam Meningkatkan Keterampilan Bahasa,” Pena Literasi, vol. 1, no. 2, p. 108, 2018, doi: 10.24853/pl.1.2.108-113. 
[9] S. N. Aini and P. Sudira, "Pengaruh strategi pembelajaran, gaya belajar, sarana praktik, dan media terhadap hasil belajar patiseri SMK se-Gerbangkertasusila," J. Pendidik. Vokasi, vol. 5, no. 1, p. 88, 2015, doi: 10.21831/jpv.v5i1.6077.

[10] O. A. K. Jayusman, Iyus and Shavab, "Studi Deskriptif Kuantitatif Tentang Aktivitas Belajar Mahasiswa Dengan Menggunakan Media Pembelajaran Edmodo Dalam Pembelajaran Sejarah,” J. Artefak, vol. 7, no. 1, pp. 13-20, 2020.

[11] A. Purwanto;, M. Asbari;, and P. B. Santoso, "Pengaruh Kompetensi, Motivasi, Kepemimpinan, Komitmen dan Budaya Kerja Sistem Manajemen Integrasi ISO 9001, ISO 14000 dan ISO 45001 pada Industri Otomotif," J. Produkt., vol. 6, no. 2, pp. 158-166, 2019, [Online]. Available: http://openjurnal.unmuhpnk.ac.id/index.php/jp/article/view/1798. 